\title{
Abscisic Acid Induces Mitogen-Activated Protein Kinase Activation in Barley Aleurone Protoplasts
}

\author{
Menno L. W. Knetsch, ${ }^{a, 1}$ Mei Wang, ${ }^{b}$ B. Ewa Snaar-Jagalska, ${ }^{a}$ and Sjoukje Heimovaara-Dijkstra ${ }^{b, 2}$ \\ a Cell Biology Section, Institute of Molecular Plant Sciences, Clusius Laboratory, Wassenaarseweg 64, 2333 AL Leiden, \\ The Netherlands \\ b Department of Plant Biotechnology, Center for Phytotechnology, Leiden University/Netherlands Organization for \\ Applied Research, Wassenaarseweg 64, 2333 AL Leiden, The Netherlands
}

\begin{abstract}
Abscisic acid (ABA) induces a rapid and transient mitogen-activated protein (MAP) kinase activation in barley aleurone protoplasts. MAP kinase activity, measured as myelin basic protein phosphorylation by MAP kinase immunoprecipitates, increased after $1 \mathrm{~min}$, peaked after $3 \mathrm{~min}$, and decreased to basal levels after $\sim 5 \mathrm{~min}$ of ABA treatment in vivo. Antibodies recognizing phosphorylated tyrosine residues precipitate with myelin basic protein kinase activity that has identical $A B A$ activation characteristics and demonstrate that tyrosine phosphorylation of MAP kinase occurs during activation. The half-maximal concentration of ABA required for MAP kinase activation, $3 \times 10^{-7} \mathrm{M}$, is very similar to that required for ABA-induced rab16 gene expression. The tyrosine phosphatase inhibitor phenylarsine oxide can completely block ABAinduced MAP kinase activation and rab16 gene expression. These results lead us to conclude that ABA activates MAP kinase via a tyrosine phosphatase and that these steps are a prerequisite for ABA induction of rab16 gene expression.
\end{abstract}

\section{INTRODUCTION}

The phytohormone abscisic acid (ABA) influences many processes in plant physiology, including seed development and germination (Black, 1983; Walker-Simmons, 1987; Kermode, 1990). It plays an important role in inducing cell differentiation during the process of embryogenesis (Rajasekaran et al., 1987; Kiyosue et al., 1992). ABA also has a critical role in stress responses and enhances adaptation to various stresses, such as drought and salt stress (Hetherington and Quatrano, 1991; Holappa and Walker-Simmons, 1995). Many genes are induced by ABA; examples include the rab16 gene from rice (Mundy and Chua, 1988), the Em gene from wheat (Marcotte et al., 1989 ), and the bifunctional $\alpha$-amylase subtilisin inhibitor (BASI) gene from barley (Mundy and Rogers, 1986).

Much effort has been expended to unravel the ABA perception and signal transduction pathways. To date, $\mathrm{Ca}^{2+}, \mathrm{pH}$, and $\mathrm{K}^{+}$have been identified as possible mediators in ABA signaling (Gehring et al., 1990; Wang et al., 1991; Heimovaara-Dijkstra et al., 1994; Ward et al., 1995). Furthermore, strong evidence has been presented that protein (de)phosphorylation plays an important role in ABA action. The ABA-insensitive locus $A B /-1$ from Arabidopsis has been found to be a PP2C-type phosphatase (Leung et al., 1994; Meyer et al., 1994). Furthermore, activity of this PP2C phosphatase seems essential for ABA

\footnotetext{
1 Current address: Department of Biophysics, Max Planck Institute for Medical Research, P.O. Box 103820, D-69028 Heidelberg, Germany.

2 To whom correspondence should be addressed.
}

regulation of $\mathrm{K}^{+}$fluxes in stomata (Armstrong et al., 1995). Recently, the involvement of tyrosine dephosphorylation in ABA-induced gene expression was shown by the use of the protein tyrosine phosphatase (PTP) specific inhibitor phenylarsine oxide (PAO) (Heimovaara-Dijkstra et al., 1996). This study piqued our interest, and we decided to investigate whether mitogen-activated protein (MAP) kinase activity is involved in ABA signaling.

MAP kinases constitute a widely distributed family of 40to $45-\mathrm{kD}$ serine/threonine kinases. MAP kinases, also known as extraceilular signal-regulated protein kinases (ERK), have been shown to be activated by many different stimuli and to be involved in cell proliferation and differentiation (Blumer and Johnson, 1994). The MAP kinase gene family has been highly conserved during evolution, with members found in such diverse organisms as mammals, Xenopus, yeast, Dictyostelium, and several plant species (Nishida and Gotoh, 1993; Nishihama et al., 1995).

In mammalian cells, several different types of signal transduction cascades lead to the activation of MAP kinases. MAP kinase signaling continues via substrates, including transcription factors such as c-Myc, c-Jun, and STE12 from yeast (Lange-Carter et al., 1993). Other known substrates are protein kinases involved in regulation of gene expression, such as the 90-kD ribosomal S6 kinase II phosphoprotein pp90 rsk and MAP kinase-associated protein MAPKAP kinase 2 (Burgering and Bos, 1995). MAP kinase activation requires the phosphorylation of a specific tyrosine and a threonine residue in the 
so-called TEY (Thr, Glu, Tyr) activation loop, which lies between regions VII and VIII of the kinase domain (Cano and Mahadevan, 1995). Several excellent reviews on the working mechanisms and scope of MAP kinase pathways have been published (see, for example, Jonak et al., 1994; Nishihama et al., 1995).

Currently, evidence is accumulating that MAP kinases play a similar, important role in plants. Several genes encoding MAP kinase homologs have now been cloned. In tobacco, two MAP kinase genes have been identified (Wilson et al., 1993; Seo et al., 1995). The tobacco nft3 gene was cloned on the basis of conserved sequence domains of MAP kinase, and it is expressed in all tobacco tissues tested. The tobacco MAP kinase homolog wound-inducible protein kinase (WIPK) was cloned as a wound-induced transcript. Two MAP kinase homologs have been identified in Arabidopsis, AtMPK1, and AtMPK2. The genes are suggested to be involved in cell proliferation (Mizoguchi et al., 1994).

In alfalfa, three cDNA clones encoding MAP kinase homologs have been identified, MsERK1, MMK1, and MMK2 (Duerr et al., 1993; Jonak et al., 1993, 1995). The MsERK1 protein, expressed in Escherichia coli, was phosphorylated on Tyr-215. The Tyr-215 residue was demonstrated to be essential for myelin basic protein (MBP) kinase activity of the protein (Duerr et al., 1993). The expression of MMK1 has been demonstrated to be cell cycle dependent, indicating a role in proliferation. In pea, a MAP kinase homolog, D5, was cloned; however, no function was suggested (Stafstrom et al., 1993). In petunia, pMEK was cloned and found to be expressed in ovary tissue (Decroocq-Ferrant et al., 1995). Finally, ASPK9 cDNA, isolated from oat aleurone cells, shows high homology to ERK1, with $47 \%$ identity with the predicted protein sequence. The expression of this MAP kinase gene is strongly down-regulated by gibberellic acid $\left(\mathrm{GA}_{3}\right)$ in oat aleurones, indicating a possible involvement of MAP kinases in gibberellin-regulated processes (Huttly and Phillips, 1995).

In plants, other genes have been found that are known to be part of a MAP kinase signaling pathway in several organisms. One example is the identification of the ethylene response mutant ctr1 gene as a putative Raf protein kinase (Kieber et al., 1993). Raf protein kinases are well-characterized upstream components of MAP kinase transduction pathways in many different organisms (Blumer and Johnson, 1994; Burgering and Bos, 1995). In addition, some groups have reported MBP kinase activity in plants. In some cases, this activity can be affected by external signals, such as elicitors, wounding, and auxin (Mizoguchi et al., 1994; Seo et al., 1995; Suzuki and Shinishi, 1995).

In this report, we show rapid and transient MAP kinase activation by $A B A$ and present direct evidence for MAP kinase activation by the phytohormone ABA. This activation was brought about by physiological concentrations of $A B A$ in vivo; submicromolar concentrations of $A B A$ were sufficient to induce both MAP kinase activity and rab16 gene expression. MAP kinase activity could be immunoprecipitated with antibodies recognizing phosphotyrosine residues. A correlation between ABA-induced MAP kinase activation and ABA-induced rab16 gene expression was demonstrated by the use of PAO. PAO inhibits both ABA-induced MAP kinase activation and gene expression. These results have led us to propose a model of ABA signal transduction involving MAP kinase and tyrosine phosphatase activation.

\section{RESULTS}

Because earlier research demonstrated that phosphorylation events are involved in ABA signaling leading to gene expression, we developed a MAP kinase assay to measure MAP kinase activity in barley aleurone protoplasts. The MAP kinase assay is based on in vivo stimulation of protoplasts with saturating concentrations of $\mathrm{ABA}\left(10^{-5} \mathrm{M}\right.$ final concentration), followed by immunoprecipitation of MAP kinase, which preferentially phosphorylates MBP in vitro.

To determine whether MAP kinase protein levels change during $A B A$ stimulation in the aleurone protoplasts, we used immunoblotting techniques to analyze protoplast protein preparations with varying stimulation times. Stimulation of protoplasts with $10^{-5} \mathrm{M}$ ABA for up to $1 \mathrm{hr}$ did not lead to any change in immunoreactive bands on an immunoblot probed with a polyclonal antibody recognizing MAP kinases from species such as mammals, Xenopus, and Dictyostelium (Figure 1). Several MAP kinase isoforms are probably present in barley aleurone protoplasts. Three positive bands between 40 and $43 \mathrm{kD}$ were revealed by the anti-ERK1 antibody. The minor band of $\sim 45$ $\mathrm{kD}$ was shown not to be specific because it also appeared on the blot after treatment with a second antibody only and did

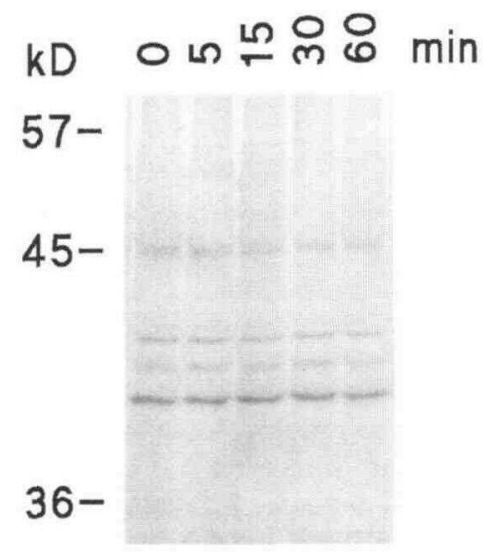

Figure 1. Protein Gel Blot Analysis of Barley Aleurone Protoplasts after Different Times of Stimulation with $10 \mu \mathrm{M}$ ABA.

Cell equivalents $\left(5 \times 10^{3}\right)$ were loaded onto a polyacrylamide gel containing $12.5 \%$ acrylamide and $0.0625 \%$ bisacrylamide. MAP kinases were visualized by probing the resulting immunoblot with a polyclonal anti-ERK1 antibody. 


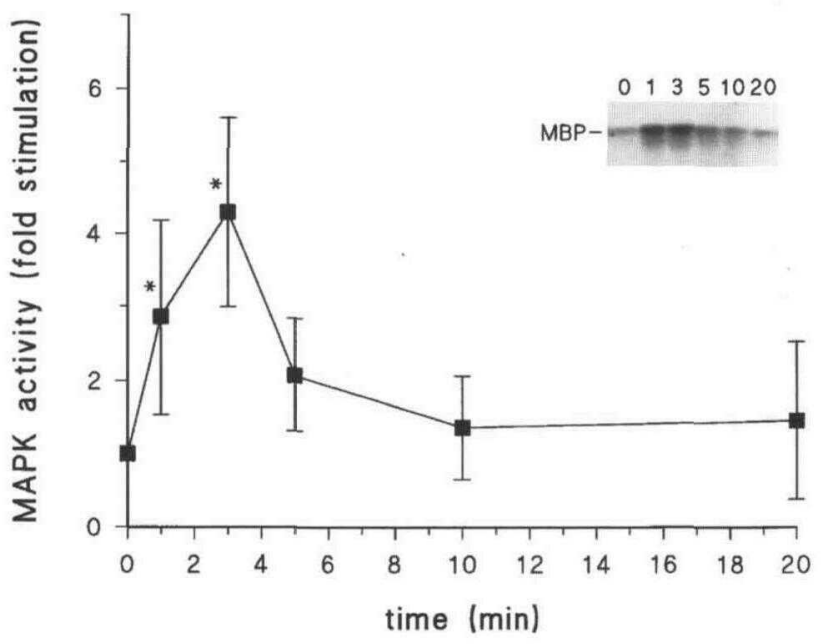

Figure 2. Time Course of ABA-Induced MAP Kinase Activity.

Protoplasts were treated with $10 \mu \mathrm{M} \mathrm{ABA}$ for the times indicated, after which MAP kinase (MAPK) activity was measured by determining MBP kinase activity on MAP kinase immunoprecipitates. MAP kinase activity is shown as the fold stimulation of the MAP kinase activity found at time zero. The mean values \pm SD of seven independent experiments are shown. The inset shows MBP phosphorylation of a typical MAP kinase experiment at $0,1,3,5,10$, and $20 \mathrm{~min}$ after $\mathrm{ABA}(10 \mu \mathrm{M})$ stimulation. $\left(^{*}\right)$ indicates significant difference with $t=0$, as determined with the Student's $t$ test $(P<0.01)$.

not appear in immunoprecipitates (data not shown). Furthermore, competition of the ERK1 antibody with a rat ERK1 "control" peptide did not reduce the intensity of this $45-\mathrm{kD}$ band. Binding of the ERK1 antibody to the other bands could be competed with this peptide, confirming its specificity (data not shown).

We then investigated whether MAP kinase activity can be activated by $A B A$ and, if so, what the kinetics of this stimulation are. Figure 2 shows clearly that $A B A$ induces a rapid and transient stimulation of MAP kinase activity. Within 1 min of ABA treatment, stimulation of MAP kinase activity could be observed. MAP kinase activity peaked at 3 min of ABA stimulation and returned to basal levels after $\sim 5 \mathrm{~min}$. The inset in Figure 2, showing a typical MBP phosphorylation experiment, demonstrates that a basal level of MBP phosphorylation activity is present in immunoprecipitates of unstimulated cells. This basal level of MBP phosphorylation may be the result of coimmunoprecipitated MAP kinases, because the antibody used potentially recognizes multiple isoforms (Figure 1). ABA caused an activation of total MBP phosphorylation up to five times basal level. Stimulation of cells with saturating concentrations of the phytohormone $\mathrm{GA}_{3}$, an antagonist of $\mathrm{ABA}$ action in seed germination (Black, 1983), did not lead to MAP kinase activation. In addition, $\mathrm{GA}_{3}$ could not inhibit $\mathrm{ABA}$ induced MAP kinase activation (data not shown).
MAP kinase is usually activated by dual phosphorylation on highly conserved threonine and tyrosine residues of the activational loop between regions VII and VIII of the kinase domain (Cano and Mahadevan, 1995). These residues are also conserved in the MAP kinases identified in plants (see, for example, Duerr et al., 1993). We tested whether MAP kinase activity in aleurone protoplasts can be immunoprecipitated by antibodies raised against phosphotyrosine residues. Indeed, phosphotyrosine antibodies immunoprecipitated MBP phosphorylation activity (Figure 3 ), which had the same ABA-inducible character as the MAP kinase response shown in Figure 2. The immunoprecipitation with the anti-phosphotyrosine antibodies of MBP phosphorylation activity could be competed by phosphotyrosine residues but not by phosphoserine or phosphothreonine residues, demonstrating the specificity of the antibody. The correlation between the MBP phosphorylation immunoprecipitated by the anti-MAP kinase antibodies and antibodies recognizing phosphotyrosine residues suggests that $A B A$ induced tyrosine phosphorylation of MAP kinase.

To investigate whether ABA-induced MAP kinase activation can be linked to other $A B A$-induced responses, we studied the ABA dose dependence of the MAP kinase response (Figure 4). After 3 min of stimulation, submicromolar concentrations

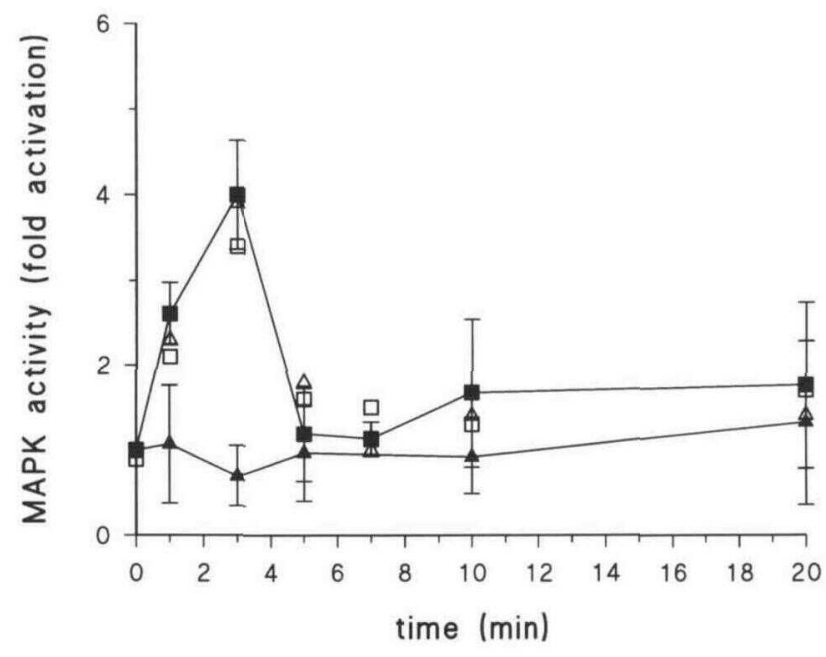

Figure 3. Time Course of ABA-Induced, Anti-Phosphotyrosine Antibody-Precipitated MAP Kinase Activity.

Protoplasts were treated with $10 \mu \mathrm{M} \mathrm{ABA}$ for the times indicated, after which MAP kinase (MAPK) activity was measured. MAP kinase was immunoprecipitated with anti-phosphotyrosine antibodies (solid squares) or with anti-phosphotyrosine antibodies in the presence of $0.1 \mathrm{mM}$ phosphotyrosine residues (solid triangles), $0.1 \mathrm{mM}$ phosphoserine residues (open squares), or $0.1 \mathrm{mM}$ phosphothreonine residues (open triangles) as (non)competetive inhibitors during the immunoprecipitation. MAP kinase is presented as the fold stimulation of the MAP kinase activity found at time zero. Mean values \pm SD of three independent experiments are shown. Competition with phosphothreonine and phosphoserine was performed once. 
of ABA induced MAP kinase activation. The half-maximal concentration of $\mathrm{ABA}$ was $\sim 3 \times 10^{-7} \mathrm{M}$, and the maximal activation of MAP kinase was fivefold.

ABA-induced MAP kinase activation can be inhibited by micromolar concentrations of the tyrosine phosphatase inhibitor PAO (Figure 5; Garcia-Moralez et al., 1990). The half-maximal concentration of PAO was $\sim 10^{-6} \mathrm{M}$. The inset in Figure 5 shows that PAO inhibited ABA-induced rab16 expression. Rab16 gene expression appeared after 15 min of ABA stimulation of aleurone protoplasts. Treatment of cells with $A B A$ in the presence of micromolar concentrations of PAO completely inhibited ABA-induced rab16 gene expression. Expression of the non-ABA-regulated control gene GAPDH was not affected, showing that this inhibition is rather specific and not caused by general inhibition of transcription. These results show that both $A B A$-induced MAP kinase activation and $A B A$-induced rab16 gene expression are dependent on tyrosine phosphatase activity.

\section{DISCUSSION}

In this report, we show that $A B A$ induces MAP kinase activation in barley aleurone protoplasts. The characteristics of this ABA-induced MAP kinase activation correlate strongly with ABA-induced rab16 gene expression. We propose a model in which MAP kinase may be involved in a signaling pathway linking $A B A$ recognition to gene expression (Figure 6).

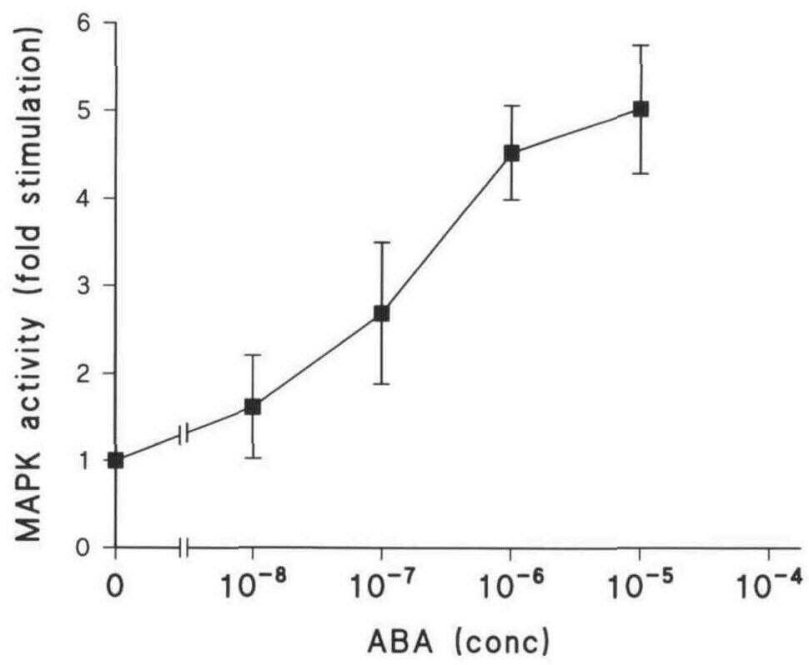

Figure 4. ABA Dose Dependence of MAP Kinase Activation.

Protoplasts were incubated with the indicated ABA concentration (conc) for $3 \mathrm{~min}$, after which MAP kinase (MAPK) activity was measured. MAP kinase activation is presented as the fold stimulation of MAP kinase activity found in cells not stimulated with $A B A$. Mean values $\pm S D$ of four independent experiments are shown.

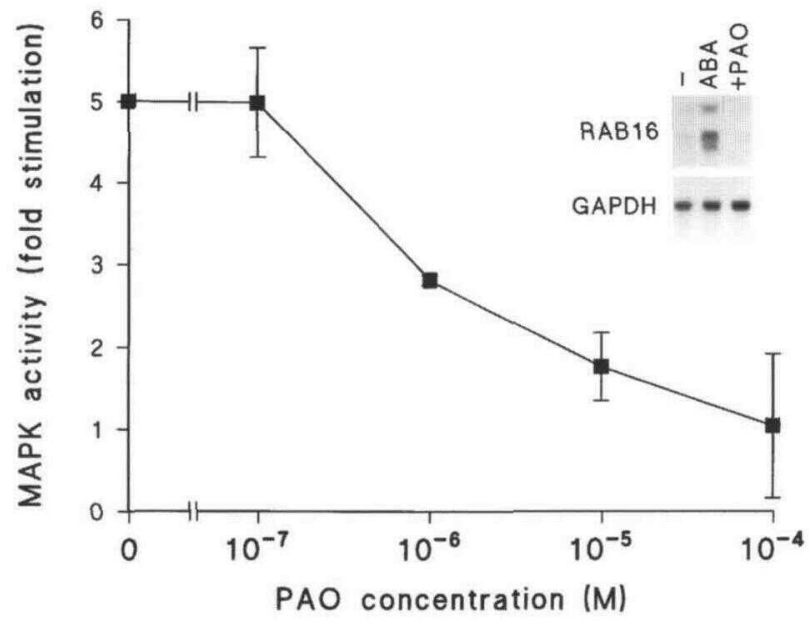

Figure 5. Inhibition of ABA-Induced MAP Kinase Activation by the Tyrosine Phosphatase Inhibitor PAO

Protoplasts were incubated for 3 min with $10 \mu \mathrm{M}$ ABA at the PAO concentrations indicated. MAP kinase (MAPK) activity is presented as the fold stimulation of the activity found in protoplasts not treated with $A B A$. Mean values $\pm S D$ of three independent experiments are presented. The inset shows PAO inhibition of ABA-induced rab16 gene expression. RNA was isolated after the stimulation of protoplasts with water $(-), 10 \mu \mathrm{M} A B A(A B A)$, or $10 \mu \mathrm{M} \mathrm{ABA}$ and $1 \mu \mathrm{M}$ PAO (+PAO). The $G A P D H$ gene is shown as an internal control for RNA quantity.

MAP kinases have been identified in several plant species (see Introduction), but only limited data on their function have been obtained. Strong data support the role of MAP kinases in wound responses; wounding rapidly induces the expression of the WIPK gene in tobacco (Seo et al., 1995). Inactivation of this MAP kinase in transgenic tobacco interferes with part of the typical wound-induced responses in tobacco. In tobacco, an MBP kinase activity has also been described that can be rapidly and transiently induced by wounding (Seo et al., 1995). Similar activation of tobacco MBP kinase activity was achieved with a fungal elicitor (Suzuki and Shinishi, 1995). Tyrosine phosphorylation is essential for the elicitor activation, suggesting that the MBP kinase activity is the result of MAP kinase activation.

Regarding phytohormone activation, the available data on MAP kinase activation concern auxin. Addition of the mitogenic hormone auxin to cell suspension cultures results in increased MAP kinase phosphorylation. Moreover, a correlation between 2,4-D addition and MBP kinase activation has been determined (Mizoguchi et al., 1994). $\mathrm{GA}_{3}$ was shown to down-regulate the expression of a MAP kinase homolog in oat (Huttly and Phillips, 1995). However, we did not find an effect of $G A_{3}$ on the MAP kinase activity in barley aleurone. In most organisms in which MAP kinase action has been characterized, it appears to play a role in cell proliferation and defense mechanisms (such as the osmotic stress response in yeast), two areas in which ABA plays a major regulatory role in plants. 
The use of barley aleurone protoplasts as a model system for ABA action has the advantage that only one cell type is present in this seed tissue. Furthermore, ABA can rapidly induce gene expression in these cells; barley rab16 RNA was expressed after 15 min of ABA stimulation (van der Meulen et al., 1993). We found that treatment of aleurone protoplasts with $A B A$ leads to a rapid and transient activation of an MBP kinase activity, which can be immunoprecipitated by an antiERK1 polyclonal antibody (Figure 2). Similar results were obtained with antibodies recognizing phosphotyrosine residues (Figure 3 ). These results make it very probable that MBP kinase activity is generated by a MAP kinase homolog. Immunoblot analysis demonstrated that three possible MAP kinase isoforms may be present in barley aleurone (Figure 1).

To investigate the possible role of ABA-induced MAP kinase activation in rab16 gene expression, we performed a doseresponse experiment. The $A B A$ concentration that led to halfmaximal activation of MAP kinase was $\sim 3 \times 10^{-7} \mathrm{M}$, which correlated well with the half-maximal $A B A$ concentration of $\sim 5 \times 10^{-7} \mathrm{M}$ for induction of rab16 gene expression (van der Meulen et al., 1993). In addition, we showed that micromolar concentrations of the PTP inhibitor PAO (Garcia-Moralez et al., 1990) block MAP kinase activation by ABA (Figure 5). It has already been demonstrated that $P A O$ can completely block $A B A$ induction of rab16 gene expression (Figure 5; HeimovaaraDijkstra et al., 1996). All of these data led to a model (Figure 6) in which ABA stimulation of barley aleurone causes activation of a tyrosine phosphatase. This PTP can activate a protein kinase and subsequently MAP kinase by stimulating tyrosine phosphorylation of MAP kinase. The phosphorylated and activated MAP kinase can further transduce the signal, leading to increased gene expression.

The model suggests a vital role for tyrosine dephosphorylation upstream of a MAP kinase in regulating hormone-induced

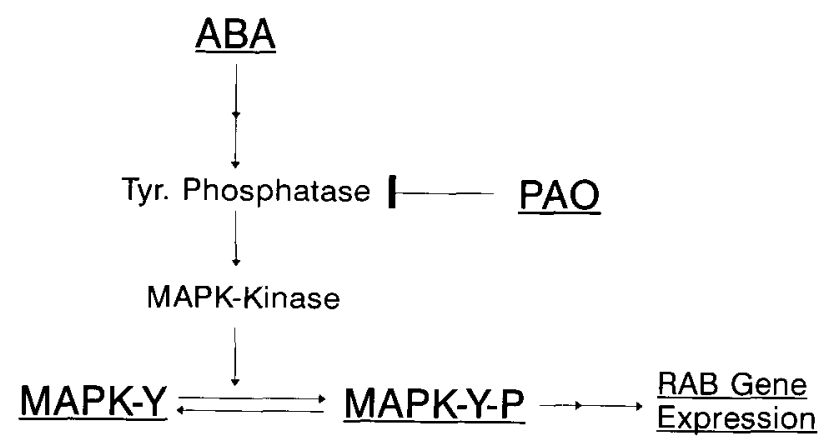

Figure 6. Model of ABA Signaling Involving MAP Kinase and Leading to rab16 Gene Expression.

Recognition of ABA leads to the activation of a tyrosine phosphatase (Tyr. Phosphatase). This PTP leads via a protein kinase (MAPK-kinase) to tyrosine phosphorylation and activation of MAP kinase (MAPK-Y $\rightarrow$ MAPK-Y-P). The activated MAP kinase can subsequently result in increased rab16 gene expression. gene expression. Although MAP kinase cascades do not usually act via phosphatase, there are several examples of such pathways. In early Xenopus oocyte development, an Src homology 2 ( $\mathrm{SH} 2)$ domain containing PTP is vital for fibroblast growth factor signaling (Tang et al., 1995). This PTP leads to activation of Ras, thereby activating the protein kinase cascade and resulting in MAP kinase activation. In rat embryo fibroblasts, a receptor PTP leads to activation of the tyrosine kinase c-Src. c-Src in turn can activate MAP kinase (Zheng and Pallen, 1994). This MAP kinase activation leads to the phosphorylation of the C-Jun transcription factor and consequently to developmental gene expression. In human embryonic kidney cells, PTP2C acts upstream of MAP kinase in the epidermal growth factor signal transduction pathway (Zhao et al., 1995). The activated MAP kinase can phosphorylate and deactivate PTP2C, resulting in negative feedback on its own activation (Peraldi et al., 1994).

All of these examples indicate that the model proposed in this report has analogies to signaling in other organisms. The exact mode of action of MAP kinase in regulation of plant gene expression is still unclear. MAP kinase could be translocated to the nucleus upon activation and directly phosphorylate transcription factors or components of the transcription machinery. MAP kinase may also be indirectly involved in the regulation of gene expression by phosphorylation of other protein kinases that exert their function in the nucleus, such as the pp90'rsk and MAPKAP kinase 2 (Burgering and Bos, 1995). Many questions concerning the pathway by which $A B A$ controls physiological events remain unanswered, but we are convinced that these data contribute to further understanding of the ABA signal transduction cascade. One question to answer is whether ABA can induce MAP kinase translocation to the nucleus.

\section{METHODS}

\begin{abstract}
Materials
$\gamma$-32P-ATP came from Amersham. The anti-ERK1 rabbit polyclonal antibody and the ERK1-control peptide were purchased from Santa Cruz Biotechnology (Santa Cruz, CA). Protein G-Sepharose 4B-fast flow was obtained from Pharmacia. The polyclonal antibody recognizing phosphotyrosine residues was a generous gift from J.A. Maassen (Department of Medical Biochemistry, Leiden University, The Netherlands). Peroxidase-labeled goat anti-rabbit antibody was from Kirkegaard and Perry Laboratories, Inc. (Gaithersburg, MD). Tablets of complete protease inhibitors were from Boehringer Mannheim (Mannheim, Germany).
\end{abstract}

\section{Barley Aleurone Protoplast Isolation and Treatment}

Barley (Hordeum vulgare cv Himalaya, harvest 1985; Department of Agronomy, Washington State University, Pullman) grains were deembryonated and cut into halves longitudinally. Grains were sterilized, aleurones were isolated, and protoplasts were prepared as described 
by Heimovaara-Dijkstra et al. (1994). The buffer used for washing and incubation of protoplasts consisted of $2 \%$ glucose, $10 \mathrm{mM}$ L-arginine, $20 \mathrm{mM} \mathrm{CaCl}_{2}, 10 \mathrm{mM}$ Mes, and $0.5 \mathrm{M}$ mannitol, pH 5.4, the osmolarity being $\sim 800$ mosmol.

\section{Protein Gel Blot and Immunoblot Analysis}

Aleurone protoplasts were resuspended in sample buffer $(60 \mathrm{mM}$ Tris, $\mathrm{pH} 6.8,10 \%$ glycerol, 5\% 2-mercaptoethanol, $80 \mathrm{mM}$ SDS) and analyzed on $12.5 \%$ polyacrylamide gels containing $0.0625 \%$ bisacrylamide. Protein was blotted to nitrocellulose. Immunoblots were probed with a 1:1000 dilution of rabbit polyclonal anti-ERK1 antibody at $4^{\circ} \mathrm{C}$ for 16 hr. Bands were visualized by peroxidase-labeled goat anti-rabbit antibody, followed by detection with diaminobenzidine staining.

\section{MAP Kinase Activity Assay}

Approximately $2 \times 10^{4}$ protoplasts per sample were treated with 10 $\mu \mathrm{M}$ abscisic acid (ABA) for various times, as indicated in Figures 2 to 5 . Each stimulation was stopped by lysing the cells in buffer $A$ ( 20 $\mathrm{mM}$ Tris, pH 8.0, $40 \mathrm{mM} \mathrm{Na}_{4} \mathrm{P}_{2} \mathrm{O}_{7}, 50 \mathrm{mM} \mathrm{NaF}, 5 \mathrm{mM} \mathrm{MgCl}, 0.1 \mathrm{mM}$ $\mathrm{Na}_{3} \mathrm{VO}_{4}, 10 \mathrm{mM}$ EDTA, $1 \%$ Triton $\mathrm{X}-100,0.5 \%$ sodium deoxycholate, $0.1 \% \mathrm{SDS}$, and one tablet of complete protease inhibitors per $50 \mathrm{~mL}$ ). The Triton-insoluble particles were removed from the lysates. Each lysate was incubated with the polyclonal anti-extracellular signalregulated protein kinase (ERK) antibody, or anti-phosphotyrosine antibody, precoupled to protein G-Sepharose to immunoprecipitate MAP kinase. The washed immunoprecipitate was incubated with $0.5 \mu \mathrm{Ci}$ $\gamma^{-32}$-ATP, $30 \mathrm{mM}$ Tris, pH 8.0, $20 \mathrm{mM} \mathrm{MgCl} 2,2 \mathrm{mM} \mathrm{MnCl}, 10 \mu \mathrm{M}$ ATP, and $7.5 \mu \mathrm{g}$ of myelin basic protein as substrate for $30 \mathrm{~min}$ at $22^{\circ} \mathrm{C}$. The mixture was electrophoresed on a $15 \%$ polyacrylamide gel, which was subsequently autoradiographed. Bands were quantified using an LKB Ultroscan densitometer (LKB Produkter AB, Bromma, Sweden).

\section{RNA Isolation and RNA Gel Blot Analysis}

Aleurone protoplasts were incubated with water, $10 \mu \mathrm{M} \mathrm{ABA}$, or $10 \mu \mathrm{M}$ $\mathrm{ABA}$ and $1 \mu \mathrm{M}$ PAO for $15 \mathrm{~min}$. RNA was isolated and blotted to a Genescreen membrane (Du Pont, Boston, MA), which was subsequently probed with rab16 and GAPDH.

Received January 23, 1996; accepted April 15, 1996.

\section{REFERENCES}

Armstrong, F., Leung, J., Grabov, A., Brearley, A., Giraudat, J., and Blatt, M.R. (1995). Sensitivity to abscisic acid of guard-cell $\mathbf{K}^{+}$ channels is suppressed by AB|1-I, a mutant Arabidopsis gene encoding a putative protein phosphatase. Proc. Natl. Acad. Sci. USA 92, 9520-9524.

Black, M. (1983). Involvement of ABA in the physiology of developing and mature seeds. In Abscisic Acid, F.T. Addicot, ed (New York: Praeger Scientific), pp. 331-363.
Blumer, K.J., and Johnson, G.L. (1994). Diversity in function and regulation of MAP kinase pathways. Trends Biochem. Sci. 19, 236-240.

Burgering, B.M.T., and Bos, J.L. (1995). Regulation of ras-mediated signaling: More than one way to skin a cat. Trends Biochem. Sci. 20, 18-22.

Cano, E., and Mahadevan, L.C. (1995). Parallel signal processing among mammalian MAPKs. Trends Biochem. Sci. 20, 117-122.

Decroocq-Ferrant, V., Decroocq, S., Van Went, J., Schmidt, E., and Kreis, M. (1995). A homologue of the MAP/ERK family of protein kinase genes is expressed in vegetative and in female reproductive organs of Petunia hybrida. Plant Mol. Biol. 27, 339-350.

Duerr, B., Gawienowski, M., Ropp, T., and Jacobs, T. (1993). MsERK1: A mitogen-activated protein kinase from a flowering plant. Plant Cell 5, 87-96.

Garcia-Moralez, P., Minami, Y., Luong, E.L., Klausner, R.D., and Samuelson, L.R. (1990). Tyrosine phosphorylation in T-cells is regulated by phosphatase activity: Studies with phenylarsine oxide. Proc. Natl. Acad. Sci. USA 87, 9255-9259.

Gehring, C.A., Irving, H.R., and Parish, R.W. (1990). Effects of auxin and abscisic acid on cytosolic calcium and $\mathrm{pH}$ in plant cells. Proc. Natl. Acad. Sci. USA 87, 9643-9649.

Heimovaara-Dijkstra, S., Heistek, J.C., and Wang, M. (1994). Counteractive effects of $A B A$ and $\mathrm{GA}_{3}$ on extracellular $\mathrm{pH}$ and malate in barley aleurone. Plant Physiol. 106, 359-365.

Heimovaara-Dijkstra, S., Nieland, T.J.F., van der Meulen, R.M., and Wang, M. (1996). Abscisic acid-induced gene expression requires the activity of protein(s) sensitive to the protein-tyrosine phosphatase inhibitor phenylarsine oxide. Plant Growth Regul. 18, 115-123.

Hetherington, A.M., and Quatrano, R.S. (1991). Tansley review no. 31: Mechanisms of action of abscisic acid at the cellular level. New Phytol. 119, 9-23.

Holappa, L.D., and Walker-Simmons, M.K. (1995). The wheat abscisic acid-responsive protein kinase mRNA, PKABA1, is up-regulated by dehydration, cold, temperature, and osmotic stress. Plant Physiol. 108, 1203-1210.

Huttly, A.K., and Phillips, A.L. (1995). Gibberellin-regulated expression in oat aleurone cells of two kinases that show homology to MAP kinase and a ribosomal protein kinase. Plant Mol. Biol. 27, 1043-1052.

Jonak, C., Pay, A., Boegre, L., Hirt, H., and Heberle-Bors, E. (1993). The plant homologue of MAP kinase is expressed in a cell-cycle dependent and organ-specific manner. Plant J. 3, 611-617.

Jonak, C., Heberle-Bors, E., and Hirt, H. (1994). MAP kinases: Universal multi-purpose signaling tools. Plant Mol. Biol. 24, 407-416.

Jonak, C., Kiegerl, S., Lloyd, C., Chan, J., and Hirt, H. (1995). MMK2, a novel MAP kinase, specifically complements the yeast MPK1 function. Mol. Gen. Genet. 248, 686-694.

Kermode, A.R. (1990). Regulatory mechanisms involved in the transition from seed development to germination. Plant Sci. 9, 155-195.

Kieber, J.J., Rothenberg, M., Roman, G., Feldmann, K.A., and Ecker, J.R. (1993). CTR1, a negative regulator of the ethylene response pathway in Arabidopsis, encodes a member of the Raf family of protein kinases. Cell 72, 427-441.

Kiyosue, T., Nakayama, J., Satoh, S., Isogai, A., Suzuki, A., Kamada, H., and Harada, H. (1992). Partial amino-acid sequence of ELP31, a carrot embryogenic-cell protein, and enhancement of its accumulation by abscisic acid in somatic embryos. Planta 185, 337-342. 
Lange-Carter, C.A., Pleiman, C.M., Gardner, A.M., Blumer, K.J., and Johnson, G.L. (1993). A divergence in the MAP kinase regulatory network defined by MEK kinase and Raf. Science 260, 315-319.

Leung, J., Bouvier-Durand, M., Morris, P.-C., Guerrier, D., Chefdor, F., and Giraudat, J. (1994). Arabidopsis ABA response gene AB/1: Features of a calcium-modulated protein phosphatase. Science 264, 1448-1452.

Marcotte, W.R., Jr., Russell, S.H., and Quatrano, R.S. (1989). Abscisic acid-responsive sequences from the $E m$ gene of wheat. Plant Cell 1, 969-976.

Meyer, K., Leube, M.P., and Grill, E. (1994). A protein phosphatase $2 \mathrm{C}$ involved in $\mathrm{ABA}$ signal transduction in Arabidopsis thaliana. Science 264, 1452-1455.

Mizoguchi, T., Gotoh, Y., Nishida, E., Yamaguchi-Shinozaki, K., Hayashida, N., Iwasaki, T., Kamada, H., and Shinozaki, K. (1994). Characterization of two CDNAs that encode MAP kinase homologues in Arabidopsis thaliana and analysis of the possible role of auxin in activating such kinase activities in cultured cells. Plant J. 5, 111-122.

Mundy, J., and Chua, N.-H. (1988). ABA and water stress induce the induction of a novel rice gene. EMBO J. 7, 2279-2286.

Mundy, J., and Rogers, J.C. (1986). Selective expression of an amylase/protease inhibitor in barley aleurone cells: Comparison to the barley subtilisin inhibitor. Planta 169, 51-63.

Nishida, E., and Gotoh, Y. (1993). The MAP kinase cascade is essential for diverse signal transduction pathways. Trends Biochem. Sci. 18, 128-131.

Nishihama, R., Banno, H., Shibata, W., Hirano, K., Nakashima, M., Usami, S., and Machida, Y. (1995). Plant homologues of components of MAPK (mitogen-activated protein kinase) signal pathways in yeast and animal cells. Plant Cell Physiol. 36, 749-757.

Peraldi, P., Zhao, Z., Filloux, C., Fisher, E.H., and van Obberghen, E. (1994). Protein-tyrosine-phosphatase $2 \mathrm{C}$ is phosphorylated and inhibited by $44-k D a$ mitogen-activated protein kinase. Proc. Natl. Acad. Sci. USA 91, 5002-5006.

Rajasekaran, K., Hein, M.B., and Vasil, I.K. (1987). Endogenous abscisic acid and indole-3-acetic acid and somatic embryogenesis in cultured leaf explants of Pennisetum purpureaum Schum. Plant Physiol. 84, 47-51.
Seo, S., Okamoto, M., Seto, H., Ishizuka, K., Sano, H., and Ohashi, Y. (1995). Tobacco MAP kinase: A possible mediator in wound signal transduction. Science 270, 1988-1992.

Stafstrom, J.P., Altschuler, M., and Anderson, D.H. (1993). Molecular cloning and expression of a MAP kinase homologue from pea. Plant Mol. Biol. 22, 83-90.

Suzuki, K., and Shinishi, H. (1995). Transient activation and tyrosine phosphorylation of a protein kinase in tobacco cells treated with a fungal elicitor. Plant Cell 7, 639-647.

Tang, T.L., Freeman, R.M., Jr., O'Reilly, A.M., Neel, B.G., and Sokol, S.Y. (1995). The SH2-containing protein tyrosine phosphatase SH PTP2 is required upstream of MAP kinase for early Xenopus development. Cell 80, 473-483.

van der Meulen, R.M., Heidekamp, F., Jastroff, B., and Wang, $M$. (1993). Effects of abscisic acid analogues on abscisic acid-induced gene expression in barley aleurone protoplasts: Relationship between structure and function of the abscisic acid molecule. J. Plant Growth Regul. 12, 13-19.

Walker-Simmons, M. (1987). ABA levels and sensitivity in developing wheat embryos of sprouting resistant and susceptible cultivars. Plant Physiol. 84, 61-66.

Wang, M., van Duijn, B., and Schram, A.W. (1991). Abscisic acid induces a cytosolic calcium decrease in barley aleurone protoplasts. FEBS Lett. 278, 69-74.

Ward, J.M., Pei, Z.-M., and Schroeder, J.I. (1995). Roles of ion channels in initiation of signal transduction in higher plants. Plant Cell 7, 833-844.

Wilson, C., Eller, N., Gartner, A., Vicente, O., and Heberle-Bors, E. (1993). Isolation and characterization of a tobacco CDNA clone encoding a putative MAP kinase. Plant Mol. Biol. 23, 543-551.

Zhao, Z., Tan, Z., Wright, J.H., Diltz, C.D., Shen, S., Krebs, E.G., and Fisher, E.H. (1995). Altered expression of protein-tyrosine phosphatase $2 \mathrm{C}$ in 293 cells affects protein tyrosine phosphorylation and mitogen-activated protein kinase activation. J. Biol. Chem. 270, 11765-11769.

Zheng, X.M., and Pallen, C.J. (1994). Expression of receptor-like protein tyrosine phosphatase $\alpha$ in rat embryo fibroblasts activates mitogen-activated protein kinase and C-Jun. J. Biol. Chem. 269, 23302-23309. 


\section{Abscisic Acid Induces Mitogen-Activated Protein Kinase Activation in Barley Aleurone Protoplasts.}

MLW. Knetsch, M. Wang, B. E. Snaar-Jagalska and S. Heimovaara-Dijkstra Plant Cell 1996;8;1061-1067

DOI 10.1105/tpc.8.6.1061

This information is current as of January 21, 2019

Permissions

eTOCs

CiteTrack Alerts

Subscription Information
https://www.copyright.com/ccc/openurl.do?sid=pd_hw1532298X\&issn=1532298X\&WT.mc_id=pd_hw15322 98X

Sign up for eTOCs at:

http://www.plantcell.org/cgi/alerts/ctmain

Sign up for CiteTrack Alerts at:

http://www.plantcell.org/cgi/alerts/ctmain

Subscription Information for The Plant Cell and Plant Physiology is available at: http://www.aspb.org/publications/subscriptions.cfm 